\title{
Impact of contractile reserve on acute response to cardiac resynchronization therapy Marie Moonen ${ }^{1}$, Mario Senechal ${ }^{2}$, Bernard Cosyns ${ }^{3}$, Pierre Melon ${ }^{1}$, Eric Nellessen ${ }^{1}$, Luc Pierard ${ }^{1}$ and Patrizio Lancellotti*1
}

Address: ${ }^{1}$ Department of Cardiology, CHU Sart Tilman, Liege, Belgium, 22725 , chemin Sainte-Foy, Québec, Canada and ${ }^{3}$ Chirec Hôpital de Brainel'Alleud Waterloo, rue Wayez 35, 1420 Braine l'Alleud, Belgium

Email: Marie Moonen - M.Moonen@student.ulg.ac.be; Mario Senechal - mario.senechal@crhl.ulaval.ca; Bernard Cosyns - bcosyns@skynet.be; Pierre Melon - pmelon@chu.ulg.ac.be; Eric Nellessen - enellessen@chu.ulg.ac.be; Luc Pierard - lpierard@chu.ulg.ac.be;

Patrizio Lancellotti* - plancellotti@chu.ulg.ac.be

* Corresponding author

Published: 3I December 2008

Cardiovascular Ultrasound 2008, 6:65 doi:10.1 | 86/1476-7|20-6-65
Received: 30 October 2008

Accepted: 3I December 2008

This article is available from: http://www.cardiovascularultrasound.com/content/6/1/65

(c) 2008 Moonen et al; licensee BioMed Central Ltd.

This is an Open Access article distributed under the terms of the Creative Commons Attribution License (http://creativecommons.org/licenses/by/2.0), which permits unrestricted use, distribution, and reproduction in any medium, provided the original work is properly cited.

\begin{abstract}
Background: Cardiac resynchronization therapy (CRT) provides benefit for congestive heart failure, but still $30 \%$ of patients failed to respond to such therapy. This lack of response may be due to the presence of significant amount of scar or fibrotic tissue at myocardial level. This study sought to investigate the potential impact of myocardial contractile reserve as assessed during exercise echocardiography on acute response following CRT implantation.
\end{abstract}

Methods: Fifty-one consecutive patients with heart failure (LV ejection fraction $27 \% \pm 5 \%, 67 \%$ ischemic cardiomyopathy) underwent exercise Doppler echocardiography before CRT implantation to assess global contractile reserve (improvement in LV ejection fraction) and local contractile reserve in the region of the LV pacing lead (assessed by radial strain using speckle tracking analysis). Responders were defined by an increase in stroke volume $\geq 15 \%$ after CRT.

Results: Compared with nonresponders, responders (25 patients) showed a greater exerciseinduced increase in LV ejection fraction, a higher degree of mitral regurgitation and a significant extent of LV dyssynchrony. The presence of contractile reserve was directly related to the acute increase in stroke volume $(r=0.48, p<0.001)$. Baseline myocardial deformation as well as contractile reserve in the LV pacing lead region was greater in responders during exercise than in nonresponders $(p<0.000 \mathrm{I})$.

Conclusion: The present study showed that response to CRT largely depends not only on the extent of LV dyssynchrony and the severity of mitral regurgitation but also on the presence of contractile reserve.

\section{Background}

The number of patients presenting with heart failure is increasing rapidly. Currently, cardiac resynchronization therapy (CRT) has emerged as an adjunctive treatment in patients with drug-refractory heart failure [1]. The clinical benefit of CRT - evidenced by improvement in symptoms, quality of life, exercise capacity, and left ventricular (LV) systolic performance - has been largely demon- 
strated $[2,3]$. Acutely, a CRT-increase in forward stroke volume by $\geq 15 \%$ has been shown to predict long-term clinical outcome in both ischemic and non ischemic cardiomyopathy [4]. However, $20 \%$ to $30 \%$ of patients do not respond to CRT despite application of recommended selection criteria [5]. Therefore, additional selection criteria are needed. Response to CRT largely depends on the extent of LV dyssynchrony, the severity of of mitral regurgitation and the possibility offers to the LV to recruit function [6-9]. CRT response could thus correlate with myocardial viability and inversely be associated with the extent of myocardial fibrosis $[10,11]$. Furthermore, scar tissue or fibrosis - characterized by lack of contractile reserve - in the LV pacing lead region may prohibit response to CRT. Myocardial contractile reserve - important prognostic marker in heart failure - can be reliably assessed during exercise echocardiography [12]. This study sought to investigate the potential impact of myocardial contractile reserve as assessed during exercise echocardiography on acute response following CRT implantation.

\section{Methods \\ Patient population}

Consecutive patients $(n=51)$ with severe heart failure, scheduled for implantation of a permanent biventricular pacemaker, were included using established selection criteria for CRT: New York Heart Association class III or IV despite optimal medical therapy, LV ejection fraction $\leq$ $35 \%$, QRS with left bundle branch block configuration or a duration $>120 \mathrm{~ms}$. The aetiologies of heart failure were idiopathic dilated cardiomyopathy in 17 patients and ischaemic heart disease in 34 . All patients underwent exercise Doppler echocardiography before CRT implantation to assess global LV contractile reserve and local contractile reserve in the region of the LV pacing lead (assessed by longitudinal strain using speckle tracking analysis). No patients with ischaemic disease presented inducible ischaemia during test. The protocol was approved by the Human Ethical Committee of our University Hospital and all patients gave informed consent.

\section{Exercise echocardiography}

A symptom-limited graded bicycle exercise test was performed in a semi-supine position on a tilting exercise table. After an initial workload of $25 \mathrm{~W}$ maintained for 2 min, the workload was increased every 2 min by $25 \mathrm{~W}$. Blood pressure and a 12-lead electrocardiogram were recorded every $2 \mathrm{~min}$. Two-dimensional echocardiographic recordings were made throughout the test.

\section{Echocardiographic measurements}

All echocardiographic parameters were obtained at rest and at peak exercise in the same cycling semi-supine position (Vivid 7 imaging device, GE Healthcare, United King- dom) and were obtained in digital format and stored on optical disks for off-line analysis. Two-dimensional grayscale images (frame rates $\geq 70 \mathrm{~s}^{-1}$ ) and colour-tissue Doppler imaging (frame rates $\geq 115 \mathrm{~s}^{-1}$ ) were performed in the apical views using a narrow sector angle. Left ventricular end-diastolic and end-systolic volumes and ejection fraction were measured by the biapical Simpson disk method. Wall motion score analysis was applied to a 16-segment model of the $\mathrm{LV}$ with a semiquantitative scoring system ( 1 = normal, 2 = hypokinesia, 3 = akinesia, 4 = dyskinesia). Quantitation of MR was performed by the proximal isovelocity surface area method as previously described [4]. Intra-LV dyssynchrony was referred to LV dispersion and was calculated as the difference between the longest and the shortest times to peak systolic velocities of 4 opposing basal walls (apical 2-and 4-chamber) [13]. Global LV contractile reserve was expressed as the change in LV ejection fraction from rest to peak exercise. Regional contractile reserve in the pacing lead was assessed using speckle tracking analysis from LV long axis images (mid segments). After tracing the endocardial borders in the end-systolic frame, an automated tracking algorithm outlined the myocardial deformation in the dedicated LV segments [14]. Peak systolic radial strain was only measured in the lateral, posterior and anterior regions, where the LV lead was positioned.

\section{CRT implantation and setting}

All patients received a biventricular pacing device for CRT with a right ventricular apical lead and LV pacing electrodes positioned through the coronary sinus in a LV epicardial vein. This coronary sinus lead was placed in a lateral position in 32 patients, in a postero-lateral position in 16 and in anterior position in 3. After a successful implant, echocardiography was used to optimize the atrio-ventricular delay in order to maximize LV filling time. Interventricular pacing interval was set to default value $(\mathrm{V}-\mathrm{V}=0 \mathrm{~ms})$.

\section{CRT response definition}

Within the week after implantation, changes in forward stroke volume were assessed. Improvement was defined as an increase in stroke volume $\geq 15 \%$ after CRT [2] (see videos).

\section{Statistical analysis}

Data are expressed as mean \pm 1 SD (STATISTICA version $6)$. Student's paired 2-tailed t test was used to compare measurements obtained at rest and during exercise. Categorical variables were compared with Fisher exact test. A value of $\mathrm{p}<0.05$ was considered significant. Categorical data are summarized as frequencies and percentages. Linear regression analysis was performed to evaluate the relation between the improvement in LV ejection fraction during exercise and the percentages of changes in forward 
stroke volume after CRT implantation. The optimal improvement in LV ejection fraction and in myocardial strain during exercise to predict response to CRT was determined by receiver operating characteristic curve analysis. To detect independent cofactors associated with response to CRT, a logistic multivariate analysis was performed. All significant variables were included in the multivariate model. Reproducibility of echocardiographic measurements has been previously published [15].

\section{Results}

\section{Responders versus non responders}

Within the 2 days after CRT implantation, 25 patients (49\%) were responders. Baseline clinical and echocardiographic parameters between responders and non responders were similar, except for higher degree of mitral regurgitation, greater extent of LV dyssynchrony and better myocardial deformation by $2 \mathrm{D}$ speckle tracking in the LV lead region in responders (Table 1). During exercise, responders showed a greater increase in LV ejection fraction. Improvement in LV ejection fraction at peak test was correlated to the improvement in forward stroke volume after CRT ( $\mathrm{r}=0.48)$ (Figure 1$)$. By multivariate logistic regression analysis, $\mathrm{LV}$ dyssynchrony $(\mathrm{p}=0.017)$, the degree of mitral regurgitation $(\mathrm{p}=0.028)$ and the presence of contractile reserve at exercise $(p=0.006)$ emerged as independent predictors of response to CRT. Table 2 depicted the area under the curves (ROC-curves) for these 3 independent predictors (Figure 2) (see additional files 1, 2, 3, 4 and 5).

\section{Regional contractile reserve and response to CRT}

During exercise, the extent of improvement in regional strain $(4.2 \pm 1.6 \%$ vs $0.44 \pm 3.5 ; \mathrm{p}<0.0001)$ was greater in patients who presented a significant increase in forward stroke volume. By multivariate logistic regression analysis, the presence of contractile reserve in the LV lead region (OR 0.6: 95\% CI 0.39-0.94; p = 0.025) and the global improvement in ejection fraction at exercise (OR 0.59: 95\% CI 0.41-0.87; $\mathrm{p}=0.008$ ) emerged as independent predictors of response to CRT. An exercise increase in strain values of the target LV lead wall by $>2 \%$ (ROCCurve) yielded a good sensitivity (92\%) and specificity (73.1\%) for predicting LV reverse remodelling after CRT (AUC 0.89). Among responders, 18 patients had both LV dyssynchrony and regional contractile reserve at exercise (Figure 3 ). Only 1 out of the 17 patients with no significant local and global contractile reserve responded to CRT. Figure 4 showed a patient without posterolateral contractile reserve during exercise.

\section{Discussion}

The response to CRT is likely modulated by multiple factors. The present study confirms that response to CRT

Table I: Responders versus non responders

\begin{tabular}{|c|c|c|c|}
\hline Variables & $\begin{array}{l}\text { Responders } \\
(n=25,49 \%)\end{array}$ & $\begin{array}{c}\text { Non Responders } \\
(n=26,51 \%)\end{array}$ & $\mathbf{p}$ \\
\hline Age, years & $71 \pm 8$ & $69 \pm 9$ & NS \\
\hline Male, n (\%) & $15(60)$ & $17(65)$ & NS \\
\hline Ischemic cardiomyopathy, n (\%) & $15(60)$ & $19(73)$ & NS \\
\hline QRS duration, ms & $154 \pm 24$ & $169 \pm 25$ & NS \\
\hline Diuretic, n (\%) & $19(76)$ & $23(88)$ & NS \\
\hline$\beta$-Blockers, n (\%) & $22(88)$ & $22(85)$ & NS \\
\hline ACEi, n (\%) & $19(76)$ & $22(85)$ & NS \\
\hline AR Blockers, n (\%) & $3(12)$ & $2(8)$ & NS \\
\hline Spironolactone, n (\%) & $9(36)$ & $14(54)$ & NS \\
\hline LV-RV dyssynchrony, ms & $54 \pm 16$ & $50 \pm 17$ & NS \\
\hline LV dispersion, $\mathrm{ms}$ & $109 \pm 44$ & $61 \pm 35$ & $<0.0001$ \\
\hline Mitral effective regurgitant orifice, $\mathrm{mm}^{2}$ & $22 \pm 11$ & $15 \pm 9$ & 0.018 \\
\hline LV end-diastolic volume, $\mathrm{ml}$ & $175 \pm 34$ & $193 \pm 42$ & NS \\
\hline LV end-systolic volume, ml & $128 \pm 26$ & $139 \pm 35$ & NS \\
\hline LV ejection fraction, \% & $27.1 \pm 5.0$ & $27.7 \pm 5.3$ & NS \\
\hline LV ejection fraction at exer., \% & $35 \pm 5.7$ & $31 \pm 5.3$ & 0.03 \\
\hline LV ejection fraction diff., \% & $8.4 \pm 2.4$ & $4.2 \pm 2.6$ & $<0.0001$ \\
\hline Wall motion score index & $2.2 \pm 0.27$ & $2.28 \pm 0.35$ & NS \\
\hline Wall motion score index at exer & $1.86 \pm 0.34$ & $2.15 \pm 0.34$ & 0.0033 \\
\hline Wall motion score index diff & $-0.3 \pm 0.26$ & $-0.13 \pm 0.21$ & 0.013 \\
\hline Strain target LV lead wall, \% & $15 \pm 2.8$ & $10.2 \pm 6.3$ & 0.0007 \\
\hline Strain target LV lead wall at exer, \% & $19.3 \pm 2.4$ & $10.7 \pm 8.5$ & $<0.0001$ \\
\hline Strain target LV lead wall diff., \% & $4.2 \pm 1.6$ & $0.44 \pm 3.5$ & $<0.0001$ \\
\hline
\end{tabular}

Ischemic cardiomyopathy, ACEi: angiotensin converting enzyme inhibitors and AR: angiotensin receptors, LV: left ventricle, RV: right ventricle. Diff: difference exercise-rest. 
Table 2: Area under the curves, sensitivity, specificity and optimal cutoff values of predictors for acute CRT response.

\begin{tabular}{|c|c|c|c|c|}
\hline Data at inclusion & Cutoff values & AUC & Sensitivity & Specificity \\
\hline LV dyssynchrony & $>65 \mathrm{~ms}$ & 0.80 & $88 \%$ & $65.4 \%$ \\
\hline Effective regurgitant orifice & $>15 \mathrm{~mm}^{2}$ & 0.69 & $76 \%$ & $57.7 \%$ \\
\hline Changes in LV ejection fraction at exercise & $\geq 6.7 \%$ & 0.89 & $84 \%$ & $76.7 \%$ \\
\hline Changes in wall motion score index at exercise & $\geq 0.23$ & 0.76 & $80 \%$ & $69 \%$ \\
\hline
\end{tabular}

largely depends not only on the extent of LV dyssynchrony and the severity of mitral regurgitation but also on the possibility offers to the $\mathrm{LV}$ to recruit function, namely the presence of contractile reserve. The probability to acutely respond to CRT is highly likely in patients with moderate to severe mitral regurgitation, major LV dyssynchrony and significant contractile myocardial recruitment - global and in the LV lead target site - at exercise.

\section{Role of LV dyssynchrony}

Several studies have demonstrated that the major predictor of responsiveness to CRT is mechanical rather than electrical dyssynchrony $[6,13,16,17]$. Among available techniques, tissue Doppler imaging has emerged as the most practical method for assessing LV dyssynchrony. As reported previously, we found that a significant mechanical delay between the basal segments of the $\mathrm{LV}$, mainly the septum and the lateral wall, on tissue Doppler was highly predictive for response to CRT $[6,18]$. Patients with a delay $\geq 65 \mathrm{~ms}$ showed a significant improvement in forward stroke volume under CRT. However, although this beneficial effect was rarely observed in patients with a delay $<65 \mathrm{~ms}, 34 \%$ (9 of 26) of the patients with severe

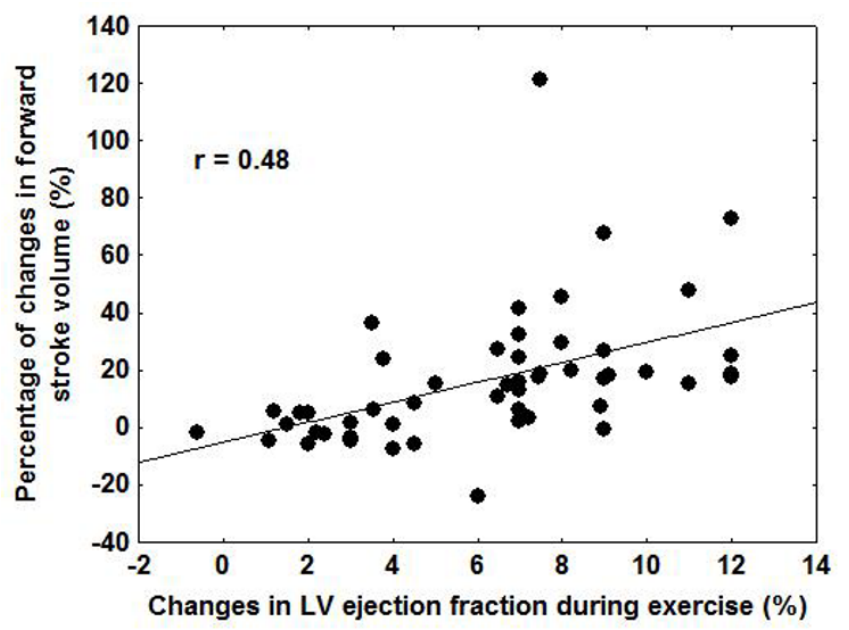

Figure I

Relationship between contractile reserve (improvement in LV ejection fraction during exercise) at inclusion and the percentage of changes forward stroke volume under CRT.
LV dyssynchrony did not respond to CRT. This emphasizes that other factors play a role; LV dyssynchrony is necessary but not sufficient for CRT response. Indeed, delayed wall motion is mainly a marker of myocardial dysfunction and could be exhibited in viable and scar tissue according to loading conditions $[19,20]$.

\section{Effect of mitral regurgitation}

Response to CRT might be modulated by the presence of functional mitral regurgitation before implantation. Few authors have shown that patients with severe mitral regurgitation have less chance of improving with CRT [3]. However, these studies included a limited number of patients. In the CARE-HF study, a randomized trial including a large number of patients, it was, conversely, shown that patients who were not improved were likely to have no significant mitral regurgitation as compared with responders [7]. The results of the present study confirm and extend this observation. Indeed, we found that a mitral effective regurgitant orifice $>15 \mathrm{~mm}^{2}$ was associated with a higher likelihood of response to CRT. Patients with more severe mitral regurgitation have more LV asynchrony (98 $\pm 49 \mathrm{~ms}$ vs $67 \pm 36 \mathrm{~ms} ; \mathrm{p}=0.019)$. The inter-

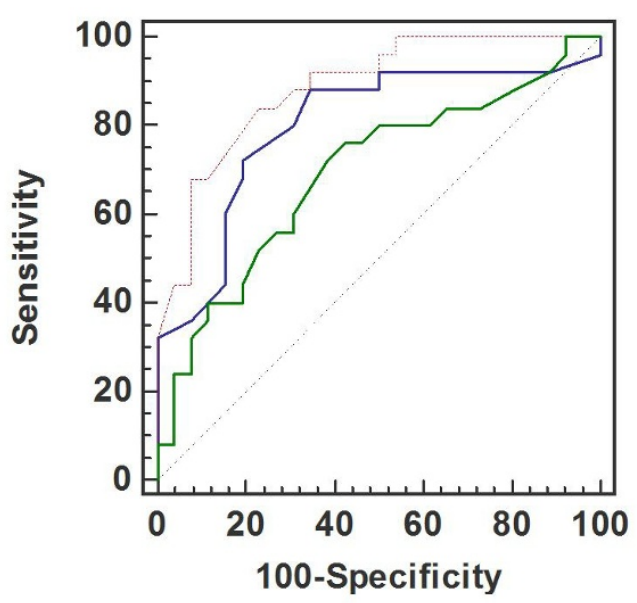

Figure 2

Receiver operating characteristic curves analysis on various parameters to predict response after CRT. Red: Changes in EF (ejection fraction), Blue: LV dyssynchrony, Green: mitral effective regurgitant orifice (ERO). 


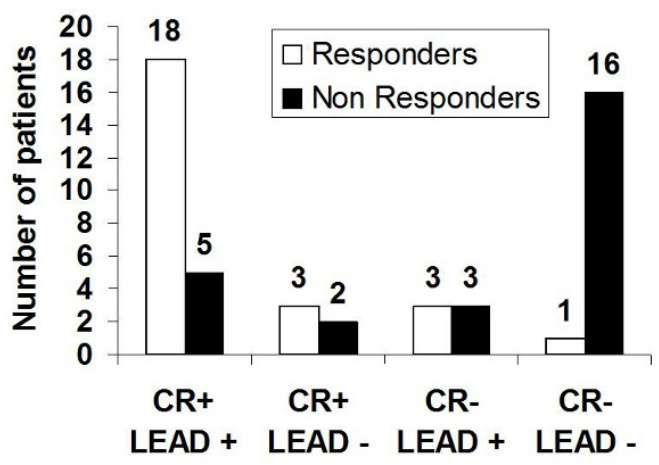

Figure 3

Number of responders to CRT for 4 different patient categories based on the presence or absence of global contractile reserve (CR+/CR-) in combination with the presence or absence of contractile reserve in the region of the pacing lead (LEAD+/LEAD-).

play between LV dyssynchrony and mitral regurgitation is complex [4,21-23]. In fact, the degree of mitral regurgitation is directly correlated to the asynchronous activation of papillary muscles and the decrease in mitral valve closing forces (mainly the consequence of global LV dyssynchrony). It could thus be expected that the beneficial effect of CRT would be greater in patients with significant mitral regurgitation.

\section{Myocardial reserve and response to CRT}

In patients with depressed LV function, the identification of contractile reserve during stress echocardiography has been shown to provide important prognostic information in heart failure patients [24,25]. More specifically, in patients referred to CRT, few authors have reported that the presence of residual myocardial viability might modulate the response to CRT [11,14,26-30]. Contractile reserve is a specific marker of underlying myocardial viability, which can be reliably assessed during semi-supine exercise echocardiography [12]. To the best of our knowledge, this study was the first to examine the value of exercise echocardiography for predicting response to CRT. Significant contractile myocardial recruitment - global and in the LV lead target site - characterized patients who presented the greater rise in forward stroke volume. An increase in LV ejection fraction by $\geq 6.7 \%$ and/or an increase in local strain by $\geq 2 \%$ were found to be predictive for response to CRT. Moreover, the extent of LV global contractile reserve was related to the percentage of acute changes in forward stroke volume. These data confirm and extend previous studies by demonstrating that a substantial amount of recruitable myocardium is needed to obtain improvement in LV function after CRT. It could be thus argued that in case of advanced myocardial remodeling process, fibrosis and loss of contractile material may severely altered myocardial conduction and contractile
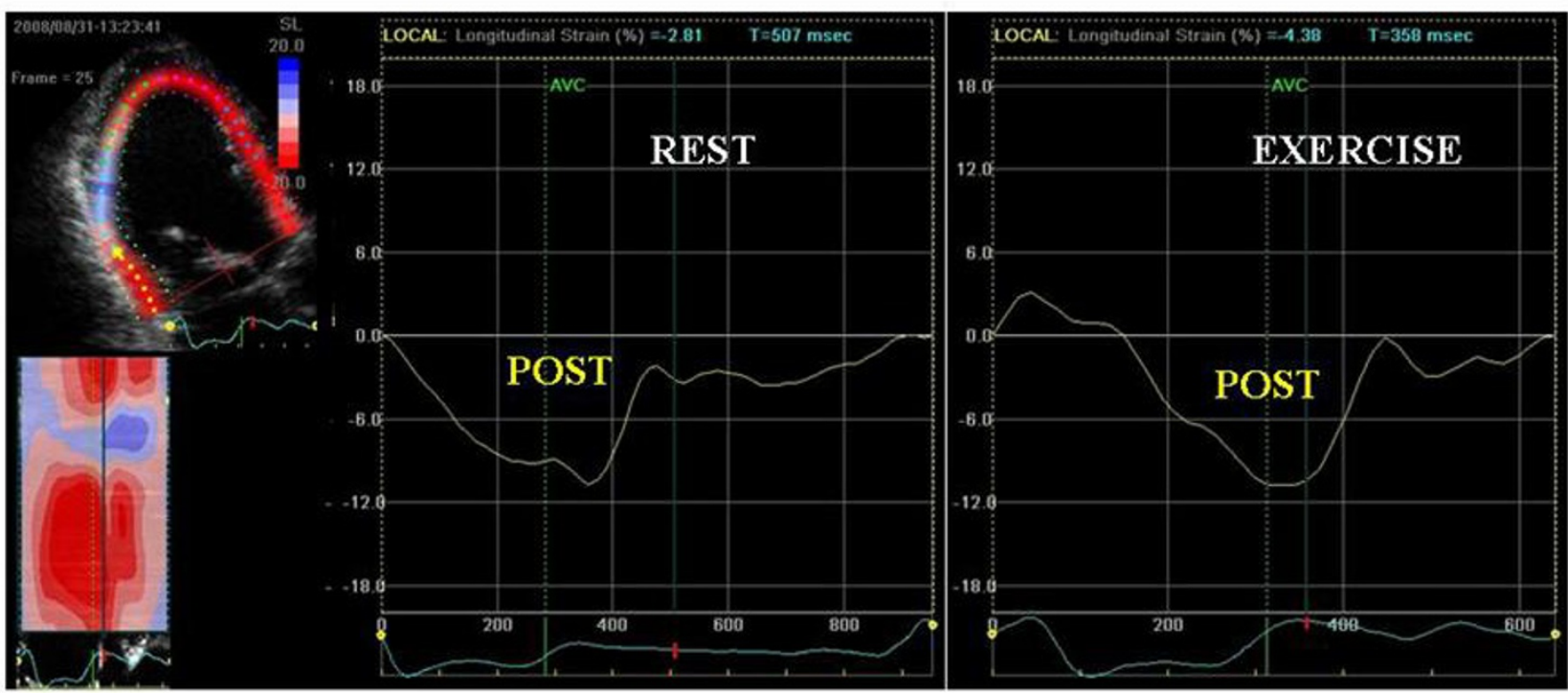

Figure 4

Example of a patient without contractile reserve in the region of the lead pacing. There is no increase in $2 \mathrm{D}$ speckle tracking strain at exercise in the posterolateral wall (POST). 
properties, which might in turn impede efficient biventricular pacing [31].

\section{Study limitations}

Some limitations should be acknowledged. Our data pertain only to patients with current criteria for CRT implantation. The population studied was not completely homogenous since it was composed of patients with myocardial dysfunction of ischaemic and non ischaemic origin. However, this represents our daily patients referred for CRT. Moreover, biventricular pacing is still a challenging therapy in both settings.

\section{Conclusion}

Heart failure patients referred to CRT have less chance of improving under therapy if they have no significant mitral regurgitation, no LV dyssynchrony and no contractile myocardial recruitment - global and in the LV lead target site - at exercise. It might thus be proposed that the assessment of these parameters would be routinely performed before submitting the patients to CRT.

\section{Competing interests}

The authors declare that they have no competing interests.

\section{Authors' contributions}

All authors participated in the conception and design of the study (MM, MS, BC, PM, EN, LP, PL). The other authors played an important role in the analysis and interpretation of data (MM, MS, BC). The last author wrote the paper (PL). All authors revised the manuscript critically for important intellectual content and gave final approval for submission (MM, MS, BC, PM, EN, LP, PL).

\section{Additional material}

\section{Additional file 1}

Case 1: a non-responder with moderate mitral regurgitation, no $L V d y$ synchrony and transmural necrosis in the posterolateral region. Under CRT, no significant change in mitral regurgitation was observed. Click here for file

[http://www.biomedcentral.com/content/supplementary/14767120-6-65-S1.avi]

\section{Additional file 2}

Case 1: a non-responder with moderate mitral regurgitation, no $L V d y s$ synchrony and transmural necrosis in the posterolateral region. Under CRT, no significant change in mitral regurgitation was observed. Click here for file

[http://www.biomedcentral.com/content/supplementary/14767120-6-65-S2.avi]

\section{Additional file 3}

Case 2: a responder with severe mitral regurgitation, $L V$ dyssynchrony and viability in the posterolateral region. Under CRT, mitral regurgitation decreased and the aortic TVI increased.

Click here for file

[http://www.biomedcentral.com/content/supplementary/1476-

7120-6-65-S3.avi]

\section{Additional file 4}

Case 2: a responder with severe mitral regurgitation, $L V$ dyssynchrony and viability in the posterolateral region. Under CRT, mitral regurgitation decreased and the aortic TVI increased.

Click here for file

[http://www.biomedcentral.com/content/supplementary/14767120-6-65-S4.avi]

\section{Additional file 5}

Cases 1 and 2 responders.

Click here for file

[http://www.biomedcentral.com/content/supplementary/1476-

7120-6-65-S5.ppt]

\section{References}

I. Vardas PE, Auricchio A, Blanc J], Daubert JC, Drexler H, Ector H, Gasparini M, Linde C, Morgado FB, Oto A, Sutton R, Trusz-Gluza M: Guidelines for cardiac pacing and cardiac resynchronization therapy: The Task Force for Cardiac Pacing and Cardiac Resynchronization Therapy of the European Society of Cardiology. Eur Heart J 2007, 28:2256-2295.

2. Tournoux FB, Alabiad C, Fan D, Chen AA, Chaput M, Heist EK, Mela T, Mansour M, Reddy V, Ruskin JN, Picard MH, Singh JP: Echocardiographic measure of acute haemodynamic response after cardiac resynchronization therapy predicts long term clinical outcome. Eur Heart J 2007, 28: I I 43-I I 48.

3. Cleland JG, Daubert JC, Erdmann E, Freemantle N, Gras D, Kappenberger L, Tavazzi L, Cardiac Resynchronization-Heart Failure (CAREHF) Study Investigators: The effect of cardiac resynchronization on morbidity and mortality in heart failure. N EnglJ Med 2005, 352:1539-1549.

4. Lancellotti P, Mélon P, Sakalihasan N, Waleffe A, Dubois C, Bertholet $M$, Piérard LA: Effect of cardiac resynchronization therapy on functional mitral regurgitation in heart failure. Am J Cardiol 2004, 94: 1462-5.

5. Abraham WT, Fisher WG, Smith AL, Delurgio DB, Leon AR, Loh E, Kocovic DZ, Packer M, Clavell AL, Hayes DL, Ellestad M, Trupp RJ, Underwood J, Pickering F, Truex C, McAtee P, Messenger J, MIRACLE Study Group. Multicenter InSync Randomized Clinical Evaluation: Cardiac resynchronization in chronic heart failure. $N \mathrm{Engl} J$ Med 2002, 346: $1845-1853$.

6. Yu CM, Gorcsan J 3rd, Bleeker GB, Zhang Q, Schalij MJ, Suffoletto MS, Fung JW, Schwartzman D, Chan YS, Tanabe M, Bax JJ: Usefulness of tissue Doppler velocity and strain dyssynchrony for predicting left ventricular reverse remodeling response after cardiac resynchronization therapy. Am J Cardiol 2007, 00(8): $1263-1270$.

7. Díaz-Infante E, Mont L, Leal J, García-Bolao I, Fernández-Lozano I, Hernández-Madrid A, Pérez-Castellano N, Sitges M, Pavón-Jiménez R, Barba J, Cavero MA, Moya JL, Pérez-Isla L, Brugada J, SCARS Investigators: Predictors of lack of response to resynchronization therapy. Am J Cardiol 2005, 95: | 436-40.

8. Reuter S, Garrigue S, Barold SS, Jais P, Hocini M, Haissaguerre M, Clementy J: Comparison of characteristics in responders versus nonresponders with biventricular pacing for drug-resistant congestive heart failure. Am J Cardiol 2002, 89:346-50.

9. Richardson M, Freemantle N, Calvert MJ, Cleland JG, Tavazzi L, CARE-HF Study Steering Committee and Investigators: Predictors and treatment response with cardiac resynchronization 
therapy in patients with heart failure characterized by dyssynchrony: a pre-defined analysis from the CARE-HF trial. Eur Heart J 2007, 28: 1827-34.

10. Bleeker GB, Kaandorp TA, Lamb HJ, Boersma E, Steendijk P, de Roos $A$, Wall EE van der, Schalij MJ, Bax Jj: Effect of posterolateral scar tissue on clinical and echocardiographic improvement after cardiac resynchronization therapy. Circulation 2006, I I 3:969-976.

II. Lim P, Bars C, Mitchell-Heggs L, Roiron C, Elbaz N, Hamdaoui B, Lellouche N, Dubois-Randé JL, Guéret P: Importance of contractile reserve for CRT. Europace 2007, 9:739-743.

12. Lancellotti P, Hoffer EP, Piérard LA: Detection and clinical usefulness of a biphasic response during exercise echocardiography early after myocardial infarction. Am Coll Cardiol 2003, I(7): I | 142-7.

13. Bax JJ, Bleeker GB, Marwick TH, Molhoek SG, Boersma E, Steendijk $P$, Wall EE van der, Schalij MJ: Left ventricular dyssynchrony predicts response and prognosis after cardiac resynchronization therapy. J Am Coll Cardiol 2004, 44: 1834-40.

14. Ypenburg C, Sieders A, Bleeker GB, Holman ER, Wall EE van der, Schalij MJ, Bax JJ: Myocardial contractile reserve predicts improvement in left ventricular function after cardiac resynchronization therapy. Am Heart / 2007, 154: I 160-I I65.

15. Lancellotti P, Cosyns B, Piérard LA: Dynamic left ventricular dyssynchrony contributes to B-type natriuretic peptide release during exercise in patients with systolic heart failure. Europace 2008, 10:496-50।.

16. Pitzalis MV, lacoviello M, Romito R, Luzzi G, Anaclerio M, Forleo C: Ventricular asynchrony predicts a better outcome in patients with chronic heart failure receiving cardiac resynchronization therapy. J Am Coll Cardiol 2005, 45:65-69.

17. Chung ES, Leon AR, Tavazzi L, Sun JP, Nihoyannopoulos P, Merlino J, Abraham WT, Ghio S, Leclercq C, Bax JJ, Yu CM, Gorcsan J 3rd, St John Sutton M, De Sutter J, Murillo J: Results of the Predictors of Response to CRT (PROSPECT) trial. Circulation 2008, I 17:2608-16.

18. Notabartolo D, Merlino JD, Smith AL, DeLurgio DB, Vera FV, Easley KA, Martin RP, León AR: Usefulness of the peak velocity difference by tissue Doppler imaging technique as an effective predictor of response to cardiac resynchronization therapy. Am J Cardiol 2004, 94:8I7-20.

19. Lancellotti P, Stainier PY, Lebois F, Piérard LA: Effect of dynamic left ventricular dyssynchrony on dynamic mitral regurgitation in patients with heart failure due to coronary artery disease. Am J Cardiol 2005, 96: I 304-7.

20. Ryf S, Rutz AK, Boesiger P, Schwitter J: Is post-systolic shortening a reliable indicator of myocardial viability? An MR tagging and late-enhancement study. J Cardiovasc Magn Reson 2006, 8:445-5I.

21. Breithardt OA, Sinha AM, Schwammenthal E, Bidaoui N, Markus KU, Franke A, Stellbrink C: Acute Effects of Cardiac Resynchronization Therapy on Functional Mitral Regurgitation in Advanced Systolic Heart Failure. J Am Coll Cardiol 2003, 41:765-770.

22. Kanzaki H, Bazaz R, Schwartzman D, Dohi K, Sade LE, Gorcsan J 3rd: A Mechanism for Immediate Reduction in Mitral Regurgitation After Cardiac Resynchronization Therapy. J Am Coll Cardiol 2004, 44:1619-1625.

23. Agricola E, Oppizzi M, Galderisi M, Pisani M, Meris A, Pappone C, Margonato $A$ : Role of regional mechanical dyssynchrony as a determinant of functional mitral regurgitation in patients with left ventricular systolic dysfunction. Heart 2006, 92:1390-1395

24. Bax JJ, Wijns W, Cornel JH, Visser FC, Boersma E, Fioretti PM: Accuracy of currently available techniques for prediction of functional recovery after revascularization in patients with left ventricular dysfunction due to chronic coronary artery disease: comparison of pooled data. J Am Coll Cardiol 1997, 30:145I-60.

25. Ramahi TM, Longo MD, Cadariu AR, Rohlfs K, Slade M, Carolan S, Vallejo E, Wackers FJ: Dobutamine-induced augmentation of left ventricular ejection fraction predicts survival of heart failure patients with severe non-ischaemic cardiomyopathy. Eur Heart J 200I, 22:849-56.

26. Hummel JP, Lindner JR, Belcik JT, Ferguson JD, Mangrum JM, Bergin JD, Haines DE, Lake DE, DiMarco JP, Mounsey JP: Extent of myo- cardial viability predicts response to biventricular pacing in ischemic cardiomyopathy. Heart Rhythm 2005, 2:12 I I-1217.

27. Da Costa A, Thévenin J, Roche F, Faure E, Roméyer-Bouchard C, Messier M, Convert G, Barthélemy JC, Isaaz K: Prospective validation of stress echocardiography as an identifier of cardiac resynchronization therapy responders. eart Rhythm 2006, 3:H406-4I3.

28. Ypenburg C, Schalij MJ, Bleeker GB, Steendijk P, Boersma E, DibbetsSchneider P, Stokkel MP, Wall EE van der, Bax J]: Extent of viability to predict response to cardiac resynchronization therapy in ischemic heart failure patients. J Nucl Med 2006, 47: I 565-1570.

29. Chalil S, Foley PW, Muyhaldeen SA, Patel KC, Yousef ZR, Smith RE, Frenneaux MP, Leyva F: Late gadolinium enhancement-cardiovascular magnetic resonance as a predictor of response to cardiac resynchronization therapy in patients with ischaemic cardiomyopathy. Europac 2007, 9:1031-1037.

30. Ypenburg C, Schalij MJ, Bleeker GB, Steendijk P, Boersma E, DibbetsSchneider P, Stokkel MP, Wall EE van der, Bax Jj: Impact of viability and scar tissue on response to cardiac resynchronization therapy in ischaemic heart failure patients. Eur Heart J 2007, 28:33-4I.

31. Kawara T, Derksen R, de Groot JR, Coronel R, Tasseron S, Linnenbank AC, Hauer RN, Kirkels H, janse MJ, de Bakker JM: Activation delay after premature stimulation in chronically diseased human myocardium relates to the architecture of interstitial fibrosis. Circulation 200I, 104:3069-75.
Publish with BioMed Central and every scientist can read your work free of charge

"BioMed Central will be the most significant development for disseminating the results of biomedical research in our lifetime."

Sir Paul Nurse, Cancer Research UK

Your research papers will be:

- available free of charge to the entire biomedical community

- peer reviewed and published immediately upon acceptance

- cited in PubMed and archived on PubMed Central

- yours - you keep the copyright

Submit your manuscript here:

http://www.biomedcentral.com/info/publishing_adv.asp
BioMedcentral 